\title{
Militares y militantes políticos: el actuar de los napoleónicos en la construcción republicana en América latina durante la independencia (1810-1835)*
}

Patrick Jacques Puigmal

\begin{abstract}
Vicerrector de Investigación y Postgrado de la Universidad de los Lagos (Chile). Correo electrónico: P_ puigmal@hotmail.com. El autor es Doctor en Historia por la Université de Pau et des Pays de I' Adour (Francia). Entre sus publicaciones recientes tenemos: "Diccionario de los militares napoleónicos durante la independencia de América Latina” (Santiago/Chile: Centro Diego Barros Arana, DIBAM, 2019. Entre sus temas de interés están: Influencia militar y política napoleónica durante la independencia de América Latina, Las élites en América Latina, Consecuencias de la dictadura militar en Chile: la exoneración de trabajadores, justicia y dictadura.
\end{abstract}

Recibido: 30 de marzo de 2019

Aprobado: 2 de mayo de 2019

Modificado: 9 de mayo de 2019

Artículo de investigación científica

DOI: http://dx.doi.org/10.15648/hc.35.2019.3

Este artículo es producto del proyecto de investigación "De civiles militarizados a militares civilizados: "La construcción de sociedades civiles en América latina (1810-1835) en la mirada de los militares napoleónicos" financiado por Conicyt/Fondecyt No 1150263.

Esta publicación está bajo una licencia Creative Commons Reconocimiento-NoComercial 4.0 
Militares y militantes políticos: el actuar de los napoleónicos en la construcción republicana en América latina durante la independencia (1810-1835)

\title{
Resumen
}

Descubrir la presencia de numerosos militares y agentes napoleónicos durante la independencia de América latina y comprobar que, más allá de sus roles militares, jugaron papeles notables en los debates y la construcción de las sociedades nuevas, apoyando la elaboración de repúblicas liberales. Lo hicieron desde el prestigio que les dio su destreza militar y utilizaron una serie de estrategias complementarias para obtenerlo: el debate público, la creación y dirección de periódicos, el desarrollo de sistemas educativos y la pertenencia a movimientos intelectuales como la masonería.

Palabras clave: militares napoleónicos, independencia, influencia, ideología.

Military and political militants: the actions of the Napoleons in republican construction in Latin America during independence (1810-1835)

\begin{abstract}
Discover the presence of napoleonic soldiers and agents during the process of the independance of Latin America and proove that, more over their military roles, they played remarkable roles in the debates and the construction of the new societies, supporting the elaboration of liberal republics. They did it from the prestige given to them by their military skills and they used a chain of complementary strategies to obtain it: the public debate, the creation and direction of newspapers, the development of educational systems and the membership of intelectual movments such as the masonry.
\end{abstract}

Keywords: napoleonic militars, independance, influence, ideology

Militares e militantes políticos: as ações dos napoleônicos na construção republicana da América Latina durante a independência (1810-1835).

\section{Resumo}

Descobrir a presença de numerosos agentes militares e napoleônicos durante a independência da América Latina e verificar que, além de seus papéis militares, eles desempenharam papéis notáveis nos debates e na construção de novas sociedades, apoiando a elaboração de repúblicas liberais. Fizeram isso a partir do prestígio que lhes deu suas 
habilidades militares e usaram uma série de estratégias complementares para obtê-lo: o debate público, a criação e administração de jornais, o desenvolvimento de sistemas educacionais e a participação em movimentos intelectuais como a Maçonaria.

Palavras-chave: Militares napoleônicos, independência, influência, ideologia.

Militaires et militants politiques: le comportement des napoléoniens dans la construction républicaine en Amérique Latine pendant 1'indépendance (18101835).

\section{Résumé}

Découvrir la présence de nombreux militaires et agents napoléoniens pendant l'indépendance de l'Amérique Latine y prouver que, au-dela de leur roles militaires, ils jouerent un role important dans les débats et la construction des sociétés nouvelles, apuyant l'élaboration de républiques libérales. Ils le firent depuis le prestige qu'ils acquérirent par leur prouesses militaires et ils utiliserent une série de stratégies pour l'obtenir: le débat public, la création et direction de journaux, le développement de systemes d'éducation et l'appartenance a des mouvements intellectuels comme la masonerie.

Mots-clés: militaires napoléoniens, indépendance, influence, idéologie.

\section{INTRODUCCIÓN}

Es todo un desafío para nosotros, describir en un artículo los resultados de veinte años de investigación, y por ello vamos a tratar de ser lo más analíticos posible. A la fecha hemos podido identificar alrededor de dos mil militares o agentes napoleónicos presentes en América latina, desde México en el norte hacia Chile y Argentina en el sur entre 1810 y $1835^{1}$. La inmensa mayoría llega para asumir un rol militar en la formación y conducción de los nacientes ejércitos independentistas pero los estudios biográficos y prosopográficos que hemos desarrollado nos permiten hoy

1 Esta investigación de casi veinte años ha sido posible gracias al financiamiento de 2 proyectos internos de la Universidad de Los Lagos (N 3540 y 3672, años 2001-2003) y de Conicyt/Fondecyt del Ministerio de Educación de Chile a través de los proyectos N 1050631 (2005-2006), 1080063 (2008-2010) y 1150263 (2015-2018), todos como investigador responsable. 
día afirmar que una proporción no menor de ellos se involucró en la vida política, social y cultural del país en el cual se radicaron. En este artículo, aludiremos a la diversidad de sus roles pero pondremos énfasis en su rol político al momento de la formación de las primeras repúblicas independientes de la zona.

No obstante, es imposible extraer este rol sin mencionar los otros porque como lo veremos más adelante, es a partir de sus éxitos militares, sus inserciones sociales y sus actuares culturales que pudieron interferir en el proceso de constitución de las sociedades nuevas.

Es importante, para iniciar este texto, precisar lo que entendemos por la expresión militar napoleónico: se trata simplemente de un militar que ha combatido en los ejércitos del imperio napoleónico. No conlleva por lo tanto ninguna connotación política menos nacional por estar este ejército compuesto por una multitud de países, regiones e identidades, todos integrados en este marco político-territorial. No obstante, la expresión militar bonapartista es muy distinta e integra la pertenencia del individuo a la filosofía política del imperio. Pero, aquí de nuevo, el término bonapartista tiene relevancias diferentes sino opuestas según el momento en el cual se emplea; un bonapartista antes de 1814 asume completamente el lado despótico del imperio mientras que el bonapartista de los años 1820 es un militante más próximo a lo popular y republicano teniendo como referencia al general Bonaparte de la Revolución Francesa, dos conceptos ausentes en la definición del primero. A esta última categoría pertenece la mayoría de los personajes registrados en nuestra investigación. Walter Bruyere-Ostells (2008) ${ }^{2}$ alude a una cuarta categoría, los napoleónistas, es decir los partidarios del emperador como persona más que como modelo político, capaces, como en Pernambuco en 1817, de intentar hacerlo escapar de Santa Elena ${ }^{3}$.

2 Walter Bruyere Ostells, La Grande Armée de la liberté, (Paris, Taillandier, 2009), 217.

3 Aprovechando la revolución liberal de Pernambuco al noreste de Brasil, un grupo de militares napoleónicos, entre ellos el coronel Latapie y los oficiales Raulet, Pontécoulant y Hartung, llegan al archipiélago. Por desgracia, la república ha cesado de existir y son arrestados. Admiten entonces que su meta, más allá de apoyar la república, era esperar la flota de Cochrane con las tropas de Brayer para ir a la isla de Santa Elena y liberar Napoleón para traerlo a América del sur. 
Lo segundo que debemos explicar es por qué este fenómeno no ha sido estudiado antes y por qué no aparece como tal en la historiografía clásica sobre el período. Todas las primeras historias nacionales se elaboran durante la segunda parte del siglo XIX y, si bien mencionan la participación individual de tal o cual napoleónico, no hacen mención a un movimiento colectivo ni a su influencia más allá de lo militar. Nuestra opinión es que los historiadores decimonónicos actuaron como agentes de la construcción del espíritu nacional para reforzar el proyecto de Estado tal cual había sido imaginado y puesto en marcho al final de las luchas de la independencia y de las guerras civiles. Diego Barros Arana ${ }^{4}$ y Benjamín Vicuña Mackenna ${ }^{5}$ en Chile, Bartolomé Mitre ${ }^{6}$ en Argentina, Juan Manuel Restrepo ${ }^{7}$ en Colombia y Venezuela, Lucas Alamán ${ }^{8}$ en México y John Armitage ${ }^{9}$ en Brasil buscan plasmar en sus historias lo que da unidad a la nación, debiendo para lograr esto dejar de lado los elementos perturbadores. Todos, además, actúan paralelamente como ministros, diplomáticos o jefes de gobiernos conservadores de la época. Mencionar dos mil militares y agentes napoleónicos en la zona en este momento y sus influencias podría haber constituido un inconveniente mayor. Cabe agregar que Europa conoció a fines del siglo XIX el mismo movimiento de creación de una historia nacional con las obras de Francois Guizot ${ }^{10}$ y Adolphe Thiers ${ }^{11}$ en Francia y de Theodor Mommsen y Barthold Niebuhr en Prussia ${ }^{12}$.

4 Diego Barros Arana, Historia General de Chile, (Santiago, Rafael Jover Editor, 16 volúmenes, 18841902).

5 Benjamín Vicuña Mackenna, La guerra a muerte: memoria sobre las últimas campañas de la independencia de Chile, (Santiago, Imprenta Nacional, 1868).

6 Bartolomé Mitre, Historia de Belgrano y de la independencia argentina, (Buenos Aires, Editorial Juventud argentina S.A., 1859) e Historia de San Martín y de la emancipación sudamericana, (Buenos Aires, Imprenta de la Nación, 3 volúmenes, 1887-1890).

7 Juan Manuel Restrepo, Historia de la revolución de la república de Colombia en América Meridional, (Besancon, Imprenta de M. Jacquin, 4 volúmenes, 1858).

8 Lucas Alamán, Historia de México, (Ciudad de México, Editorial Jus, 5 volúmenes, 1849-1852).

9 John Armitage, Historia do Brasil desde a chegada da familia de Braganza em 1808 até a abdicacao do imperador D. Pedro I em 1831, (Rio de Janeiro, Typ. Imp. E. Const. De J. Villeneuve e comp., 1837).

10 Francois Guizot, Histoire de la civilisation en France, (Paris, Didier Libraire-Éditeur, 4 volúmenes, 1830).

11 Adolphe Thiers, Histoire de la Révolution Francaise, (Paris, Furne et compagnie Libraires-Éditeurs, 10 volúmenes, 1851-1853) y Histoire du Consulat et de l'Empire, (Paris, Paulin Libraire-Éditeur, 20 volúmenes, 1846-1862).

12 Enrique Moradiellos, el oficio del historiador, (Madrid, Siglo XXI, 2010), 117, en el cual alude a estos dos historiadores prusianos como fundadores del nacionalismo prusiano a través de sus textos. 


\section{Forjadores de LOS EJÉRCitos NUEVOS}

Estos dos mil individuos llegan en su inmensa mayoría entre 1812-13 y 1825-26. Si bien la mayoría de ellos deben ser catalogados como militares, otros pertenecen al género de los agentes secretos o espías, lo que significa roles e influencias distintas. No obstante, en muchos casos, no existe ninguna contradicción con la pertenencia simultánea a estas dos categorías. Para dar cuenta de la profundidad de la investigación que hemos llevado a cabo, hemos publicado en tres volúmenes el Diccionario de los militares napoleónicos durante la independencia de América Latina ${ }^{13}$. Esta base de datos permite entender la relevancia de esta migración original a nivel militar, político, social y cultural y nos servirá de argumentación y de fuentes para la elaboración de este texto. Debemos precisar que nunca consideramos un militar como únicamente eso; es una persona que nació en un contexto cultural, que tiene una familia, una identidad, una educación, que no es obligatoriamente el resultado exclusivo de su formación militar y, como consecuencia, existen confrontaciones políticas entre militares, especialmente durante el momento de la independencia, porque no todos comparten la misma ideología o el mismo concepto de sociedad a construir. No obstante estas diferencias, cabe señalar desde ya que la inmensa mayoría de los napoleónicos puede ser catalogada como liberal republicano con meta a remplazar el régimen real colonial por la república. De los dos mil, no más de treinta deben ser considerados como conservadores, es decir a favor del mantenimiento de la monarquía. No debe sorprender esta pertenencia masiva al campo liberal republicano si consideramos que fueron educados durante la revolución francesa o en los "liceos imperiales" creados por Napoleón y en los cuales, contrariamente a lo que podría hacernos suponer el carácter dictatorial del régimen imperial, recibieron una formación basada en los principios revolucionarios de libertad, igualdad y fraternidad. También vivieron la aplicación del Código Civil y de la libertad religiosa. Es decir, siendo no todos conformes con el modelo político imperial (lo que no se contradice con una veneración si no un respeto hacia

13 Los tres volúmenes han sido publicados por el Centro de Investigación Diego Barros Arana de la Biblioteca Nacional de Santiago, el primero en 2013, el segundo en 2015 y el tercero durante este año 2019. 
el emperador), todos rechazan la vuelta de los borbones al trono y muchos participan en las rebeliones liberales fracasadas de Francia, Italia, Nápoles o España en los años 1820. El subcontinente latinoamericano representa entonces para ellos una solución a sus problemas: permite la lucha contra los borbones, contra España donde muchos pelearon entre 1808 y 1813, contra la monarquía y para instaurar un modelo republicano más cercano a sus ideales. No podemos eliminar la aventura como motor de su exilio; lo que descartamos es considerarlos como mercenarios porque, a pesar de no recibir regularmente sus pagos, se casan y se radican definitivamente en América. Menos del quince por ciento volverá definitivamente a Europa a menudo a causa de los problemas políticos que causaron sus acciones.

Llegan como militares pero desde el inicio indican claramente cuál es su opinión política como lo muestran las siguientes declaraciones pronunciadas en momentos y contextos distintos por los que combatieron principalmente en Chile y Argentina pero que se pueden extender a todo el subcontinente: Federico Brandsen, "Soy francés y aventurero. Desde Caracas hasta Chiloé y desde Chiloé hasta Buenos Aires, el suelo americano está humeando con la sangre de los aventureros de todas las naciones que han perecido en defensa de su libertad... Esta aventura tenía como meta la independencia de esta gran región del mundo"14; Maurice Persat, "Yo vine para servir la causa de los independentistas"15; Robert, "Deje Francia para vivir en un país independiente y libre"16; Marc Mercher, "Me entusiasmé por la independencia de América y dejé Francia para servir la causa de la libertad"17; Jacques Roul "¡Americanos! Cuando vine a sus regiones, tenía los mismos sentimientos que me habían caracterizado en los ejércitos franceses. Quiero pensar que nunca dudaron de mis sentimientos hacia su

14 Federico Brandsen, Diario de la campaña del sur de Chile al Bio Bio desde el 5 de noviembre de 1818 al $1^{\circ}$ de marzo de 1819, (Buenos Aires, Federico Santa Colonia Brandsen, 1910), 53.

15 Maurice Persat, Mémoires de Persat, 1806-1844, (Paris, Plon-Nourrit, 1910), 226.

16 José Rondeau, Resumen documentado de la causa seguida y sentenciada en el tribunal de la comisión militar de esta capital contra los reos Carlos Robert, Juan Lagresse, Agustín Dragumette, Narciso Parchappe y Marcos Mercher por el delito de conspiración contra las Supremas Autoridades de las Provincias Unidas y de Chile en Sud América, (Buenos Aires, Imprenta de la independencia, 1819), 10.

17 Rondeau, 1819, 14. 
causa"18; Félix Deslandes, "Viendo la patria fuera de peligro, pienso que me puede ser permitido ocuparme de mis intereses personales después de haber cumplido con los intereses comunes"19, Jorge Beauchef, "Me retiraba después de haber servido la causa de un país según mi consciencia liberal enemiga de la tiranías"20; Santiago Blaye, "Habiendo ya cesado los peligros de la patria por el resultado de la victoria de Maipú a que asistí..."21; Joseph Bacler d'Albe, "Después de la batalla de Maipú, estamos preparando el gran golpe que dará libertad a la América del sur, la conquista de Lima"22; Alexandre Danel, "y cuando al fin, Francia ya no era más la tierra de la libertad y yo soñaba con combatir por los pueblos oprimidos, me embarqué hacia estas tierras con Bruix, Viel, Bardel, Brandsen y Rauch que habían combatido al lado de Napoleón"23; Ambroise Cramer, "sobrepasado por el disgusto y las humillaciones, proscrito por los que deberían defendernos, tomé la penosa decisión de ir a América... para ofrecer mis servicios a la nueva cuna de la libertad"24; Michel Brayer, "Yo fui uno de eso hombres (hace referencia a los soldados de la Revolución que llegaron a ser generales), y vuelta a América la revolución, aunque distante de su cuna, habiéndome conducido a estos países por una porción de desgracias, llegué a ella con los títulos que acabo de presentar" ${ }^{25}$; Eustache Bruix en su lecho de muerte "sus últimas palabras fueron para Napoleón y la independencia de Chile"26. Sentimientos que el historiador Fernando Campos Harriet describió así: "todos lucharon para la emancipación americana y mostraron a través de sus actos, cada uno a su manera, la influencia del

18 Santiago Roul, texto anónimo y manuscrito en Sala Medina, Biblioteca Nacional de Santiago de Chile, AAG 2359.

19 Cartas de renuncia de Deslandes, Archivo Nacional de Chile, Ministerio de la Guerra de Chile, Volumen 19, p. 27 y volumen 59.

20 Patrick Puigmal, Memorias de Jorge Beauchef, (Santiago, Centro de Investigación Diego Barros Arana, Biblioteca Nacional de Chile, 2005), 267.

21 Patrick Puigmal, Dialogo de sordos entre José de San Martín y Michel Brayer, Cartas, artículos y manifiestos argentinos, chilenos y franceses durante la independencia de Chile, (Osorno, Universidad de Los Lagos, 2003), 92.

22 Puigmal, Dialogo de sordos, 91-92.

23 Ernesto Sabato, Sobre héroes y tumbas, Buenos Aires, Sudamericana, 1961, 83.

6224 Andrés Rodríguez, Ambrosio Cramer, un soldado de la libertad, Boletín de la Academia Nacional de Historia, Buenos Aires, 1956, Tomo XXVII, pp. 68-69.

25 Puigmal, Dialogo de sordos, 92.

26 Puigmal, Dialogo de sordos, 115. 
gran hombre que les había formado"27. Los propios líderes de la independencia reconocen su aporte. Simón Bolívar, por ejemplo, declara en 1819 a Nicolas Joly, un importante capitán de nave, "Usted es un hermano que contribuirá a expulsar al enemigo de la patria al paso que a consolidar los fundamentos de su libertad"28.

En toda América Latina, se distinguieron en la conducción de los ejércitos y obtuvieron los más altos rangos. Para citar algunos ejemplos ${ }^{29}$ : Nicolás Raoul e Isidoro Saget, generales conductores del ejército federalista de la Confederación Centroaméricana (1825-32); Adrián Woll, Giuseppe Stavoli y Carlos Beneski, coroneles del estado mayor de Santa Anna en Texas (1829); Pierre Labatut, general en jefe del ejército independentista de Brasil en 1822; Benjamín Viel y José Rondizzoni, conductores del ejército de Freire en la batalla de Lircay en Chile (1830); Manuel Serviez y Josep Sarda, generales del ejército de Bolívar en Colombia en 1818 y en 1827; Benjamín Viel y José Rondizoni, los dos únicos napoleónicos con grado de general en Chile; Federico Brandsen, coronel jefe de la caballería del general Alvear en Ituzaingo en Argentina (1826); Federico Brandsen y Pierre Raulet, generales del ejército peruano en 1825; Hipólito Bouchard, almirante la armada peruana en 1830; Renato Beluche, almirante de la armada de Colombia en 1823 y Emile Mallet, mariscal y creador de la artillería brasileña. La lista es larga de los que alcanzaron los más altos grados, señal evidente de su pericia militar. De los dos mil, quinientos veinticinco fueron oficiales superiores, ciento cuarenta en Argentina, Chile y Perú, dos cientos dieciséis en los países bolivarianos (veinticuatro generales, tres almirantes y treinta y ocho coroneles), y ciento nueve en México, Centroamérica, Caribe y Brasil (veintiún coroneles, cinco almirantes y treinta y dos generales). En total, setenta obtendrán los grados de general, mariscal (Emile Mallet en Brasil) o almirante, es decir, estuvieron en posición de

27 Fernando Campos Harriet, Soldados de Napoleón en la independencia de Chile, en Memorial del Ejército de Chile, $\mathrm{N}^{\circ}$ 350, julio-agosto de 1969.

28 Archivo General de la Nación, Colombia (AGNC), Sección venezolana, 13, archivo de la Gran Colombia, Guerra y Marina, 448.

29 Todos los datos entregados en el párrafo siguiente se encuentran en los tres volúmenes del diccionario ya citado. 
mando de ejércitos o escuadras, definiendo batallas, campañas y, en muchas ocasiones, participaron de la sobrevivencia de la independencia o de uno de los modelos de Estado en construcción. Por lo tanto, no cabe ninguna duda de su destreza militar y del aporte en que consistieron.

Más allá de distinguirse en los campos de batalla, constituyeron un elemento primordial a la hora de formar las primeras generaciones de oficiales. Recordemos que los ejércitos de la corona española o portuguesa contaban con pocos oficiales americanos razón por la cual, al inicio de las guerras emancipadoras, las tropas recientemente levantadas para combatir sufrían una gran escaza de oficiales experimentados. Todas las primeras escuelas militares, en particular la creada por Bernardo O'Higgins en 1817, cuentan con los napoleónicos como profesores o instructores. Jorge Beauchef, Antonio Arcos, Pedro de la Peña, Félix Deslandes y Ambrosio Cramer constituyen la totalidad de la planta docente de la primera escuela militar de Chile, lo mismo pasa en Argentina con los hermanos Juan Francisco, Enrique y Antonio Paillardelle en el ejército del norte del general Belgrano, con Felipe Senillosa en la primera academia militar, con Antonio Castellini en la primera escuela náutica. En Venezuela, Manuel Serviez, Manuel Cortes de Campomanes, José Schombourg, Laurent Rouvray y Pierre Labatut ayudan desde 1812 Francisco Miranda a crear su primer ejército. En las tropas de Bolívar, dieciséis napoleónicos son instructores, diecinueve asumen funciones de administración militar, y quince desarrollan ciencias nuevas como la cartografía, la topografía y la medicina militar. José Bacler d'Albe es el creador de la topografía en Chile y Perú, Clemente Althaus de la cartografía en Perú, Giovanni Codazzi de la misma ciencia en Colombia, Abel Brandin y Teodoro Schliemann de la medicina militar en Perú y Argentina. Muchos asumen roles en los estados-mayores donde definen las estrategias, establecen los planos de batallas y llevan a cabo la gestión de las tropas. Para dar un ejemplo más, el once por ciento del estado mayor del ejército de los Andes del general José de San Martín es de origen napoleónico en $1817^{30}$.

30 Todos los datos sobre su rol formador se encuentran en Puigmal Patrick, Los organismos de formación de los ejércitos de Argentina y Chile bajo la influencia napoleónica (1810-1830) en Puigmal Patrick (Coord.), El lazo de los Andes, (Osorno, Universidad de Los Lagos, Programa de Estudios y Documentación en Ciencias Humanas, 2007), 119-136. 
Para concluir con este tema, podemos afirmar que su rol fue mayor en la formación, composición y conducción de los ejércitos emancipadores. Se inspiraron de su experiencia pero, igualmente, trajeron a América los tratados de los principales estrategas de la época, en su mayoría de la Grande Armée tales como Jomini, Rogniat, Thiébault o Cormontaigne, obras presentes también en las bibliotecas de los principales líderes de la emancipación, Simón Bolívar y José de San Martín. Hasta sus enemigos reconocieron su aporte. Tal como el coronel español José Rodríguez de Ballesteros quien declara a propósito de sus campañas en Chile y en Chiloé (1813-1826):

"En medio de aquellos americanos valientes defensores de la libertad y la independencia de su patria, había extranjeros fieles a la causa, en cuyo obsequio habían perecido tantos otros paisanos suyos. Entre los que sobrevivían a tantos peligros y tantas fatigas, se hallaban hombres que habían combatido en las orillas del Guardiano y del Rin y habían presenciado el incendio de Moscú y la capitulación de Paris. Tales eran los hombres reunidos en aquel punto, haciendo causa común: Americanos y Europeos, todos estaban animados del deseo unánime de asegurar la existencia política de un vasto continente ${ }^{31}$ ".

No es intención nuestra afirmar que sin ellos los países nacientes no se hubiesen levantado o que sus ejércitos no hubiesen podido vencer a tan grandes tradiciones militares como la española o la portuguesa. Tan solo, queremos dar a conocer un fenómeno poco estudiado, otorgarle su real importancia, más allá de los afanes nacionalistas a menudo reduccionistas, y así aportar una piedra más a la comprensión del inmenso cambio social que representó en el continente el pasar de la monarquía colonial al Estado republicano independiente. Tampoco, es afán nuestro ahondar en el eurocentrismo como factor principal de explicación a todo lo ocurrido en

31 José Rodríguez Ballesteros, Historia de la revolución y guerra de la independencia del Perú desde 1818 hasta 1826, (Santiago, Biblioteca Nacional, Colección de historiadores y documentos relativos a la independencia de Chile, Tomo XXXIV, 1949), 295-296. 
el continente. Estamos hoy, aún más que cuando empezamos esta investigación, convencidos que la presencia napoleónica fue, a partir, de todas sus vertientes, un acelerador de un proceso que sin duda se venía.

Accionar militar, actuar político, inserción por el matrimonio, formación educativa e intelectual constituyeron los principales pilares de la presencia napoleónica en el continente. Vimos ya el accionar militar, nos vamos a dedicar en esta segunda parte a describir el actuar político, el cual tiene varias aristas: prensa, educación, acercamiento a los líderes y participación en grupos de influencia como, por ejemplo, la masonería.

\section{ACTORES DE LA CONSTRUCCiÓN REPUblicana}

Los militares, como todos los sujetos, son siempre portadores de ideología y, para ellos, cada conquista o participación en una campaña significa un espacio donde plasmarla. Esto es particularmente veraz con los ejércitos republicanos: sus componentes no tienen las mismas características sociales, culturales, filosóficas y políticas que los de un ejército monárquico tradicional. Los napoleónicos que llegan a América, si bien no lo hacen con el espíritu de una conquista, sienten con frecuencia el deber de participar en el quiebre del modelo monárquico, tal como lo demuestran en los escritos que han dejado ${ }^{32}$. Lo que hacen es participar en la caída de un modelo monárquico de larga data con, además, tres cientos años de práctica colonial. Es casi imposible determinar las ideologías a través del contenido de los archivos tradicionales, sean nacionales, provinciales o militares. Las encontramos en documentos privados como correspondencias, diarios o memorias que hemos podido obtener gracias a un paciente trabajo de búsqueda de sus descendientes tanto en América como en Europa. Uno no escribe a su hermano, su padre o su prometida como a su superior jerárquico, por lo

32 Ver por ejemplo Las memorias de Jorge Beauchef (Puigmal, 2005), los diarios de Federico Brandsen (Patrick Puigmal y Armando Cartes Montory, De la Alsacia al Bio Bio, el oficial napoleónico Frédéric de Brandsen en las campañas de la independencia de Chile, Concepción, Editorial Pencopolitana, 2008), las cartas de José Bacler d'Albe (Patrick Puigmal, ¡Diablos, no pensaba en Chile hace tres años! Cartas inéditas sobre la independencia de Chile, Argentina y Perú, 1817-1825, Osorno, Universidad de Los Lagos, 2006) y los dos mil documentos manuscritos de Benoit Chasseriau sobre Cartagena, Colombia, Venezuela y el Caribe entre 1812 y 1832 que nos comunicó su descendiente Jean-Baptiste Nouvion. 
que el estudio prosopográfico de aquella documentación permitió revelar, entre otros elementos, el componente ideológico de estos personajes. Su adscripción, como lo señalamos anteriormente, al liberalismo republicano conlleva consecuencias a menudo nefastas para ellos. Participan en complots, son arrestados y condenados a dadas de baja del ejército, penas de cárcel, expulsiones de la región o del país y, en algunos casos, ejecuciones. Las zonas de México y del Caribe, por ser próximas a los Estados Unidos de América del norte y por representar un paso directo hacia el sur, constituyen desde el inicio de la Revolución Francesa hasta el fin de la independencia un territorio privilegiado para intentos, invasiones y complots. Las redes de agentes secretos de Napoleón y de José Bonaparte (primero rey de España y luego exiliado en los Estados Unidos) actúan para, en un primer tiempo, incorporar las colonias al imperio napoleónico ${ }^{33} \mathrm{y}$, luego, apoyar los esfuerzos independentistas. Bernardo Sassenay, Alejandro Dauriac y Julián Mellet participan por ejemplo en un intento fallido en 1808 de llevar armas y pertrechos militares al Río de la Plata. Si agregamos las tentativas para apoyar el exemperador Napoleón desde Santa Elena a partir de 1815 y los deseos de independencia de varias islas del Caribe, no debe sorprender el número importante de agentes secretos o espías (a menudo militares activos o jubilados) napoleónicos que se encuentran en esta zona.

Iniciaremos esta segunda parte con las consecuencias de su actuar político sobre sus vidas y carreras militares. Luego, veremos cómo se involucraron en la educación de las poblaciones a través de dos acciones complementarias: la creación, dirección y redacción de periódicos y la creación y dirección de escuelas. Finalmente, abordaremos su pertenencia a movimientos profundamente políticos como fueron la masonería y el carbonarismo.

En Argentina, Chile y Perú, el veintitrés por ciento de ellos (de los tres cientos cuarenta en total identificados en este espacio) vivió suspensión,

33 Luego de la conquista de España y de la instalación de José Bonaparte como rey, el imperio envió numerosas misiones hacia diferentes puntos de América para obtener su adhesión al imperio lo que, a pesar de algunas primeras voluntades favorables, no prosperaron. A partir de 1810, Napoleón cambio de estrategia y propuso apoyar los independentistas con una sola condición: que no pasen acuerdos comerciales o políticos con Gran Bretaña; Bolívar desde Colombia, firmó por el intermedio del oficial Delpech un convenio de cooperación en 1813 pero las primeras derrotas del imperio impidieron su aplicación. 
arresto, condena y/o expulsión, la inmensa mayoría por razones políticas: Se acercaron a los líderes quienes, según su percepción, correspondían a sus ideales. Colaboraron por ejemplo con José Miguel Carrera y Carlos Alvear entre 1816 y 1821 lo que les causó muchos problemas con José de San Martín, Bernardo O’Higgins y Juan Martín de Pueyrredon y, en algunos casos la muerte como durante el "complot de los franceses" en 1818 en Buenos Aires que terminó con el fallecimiento de Jorge Yung durante su arresto, el fusilamiento de Carlos Robert y Juan Lagresse y la expulsión de Narciso Parchappe y Agustín Dragumette después de un juicio expeditivo. Otros como José Bacler d'Albe y Antonio Arcos, cercanos de San Martín, sufrieron las consecuencias de la famosa entrevista de Guayaquil en 1822 con Bolívar y su resultado: el abandono del Perú y el exilio definitivo del general argentino. En Chile, trabajaron entre 1823 y 1828 con Ramón Freire (en particular Benjamín Viel, José Rondizzoni y Pedro Chapuis) y perdieron todo al momento de la derrota de Lircay contra las fuerzas conservadoras en 1830 (entre otros Viel, Rondizzoni, Tortel, Labbé, Holley, Chapuis y Guticke). Les costó como Viel y Rondizzoni, más de diez años de exilio antes de poder retornar al país y retomar sus carreras militares. Pedro Chapuis nunca regresó y siguió su peregrinación liberal primero en Perú, luego en Colombia con Bolívar del cual se separó rápidamente y finalmente volvió a Francia, ya de edad. Manuel Labbé obtuvo una licencia absoluta con goce de fuero y uso del uniforme en 1829, fue dado de baja en 1830, se sublevó en 1832 y, arrestado, todo esto en plena guerra civil, fue expulsado a Perúu ${ }^{4}$. Luego del alejamiento de los hermanos Carrera y del asesinato de Manuel Rodríguez en Chile en 1818, José Rondizzoni decidió retirarse por "aquellos desgraciados sucesos que lastimaron su alma profundamente y formó desde entonces la resolución de separarse del servicio, protestando así contra estos actos... ${ }^{35}$ ". En Argentina, pagaron sus abanderamientos entre unitarios y federales, entre caudillos, entre provincias y en las fricciones entre Argentina, Uruguay y Brasil. En el Perú, favorables a Riva Agüero como Raulet, Brandsen, Soyer o Allier, fueron arrestados por Bolívar y exiliados en 1824-1825. El historiador argentino

34 Claudio Maldonado, El ejército chileno en el siglo XIX: génesis histórica del ideal heroico, 18101885, en www.geocities.com/capitolhill/7109/eje1.html (Fecha de consulta:abril de 2003).

35 A. Ibañez, José Toribio Medina, Hoja de servicio de don José Rondizzoni, (Santiago, Imprenta del Ferrocarril, 1865), microfilm, Biblioteca Nacional, 8. 
Herbe Pelosi escribe "los emigrados políticos de los ejércitos imperiales, los estudiosos y políticos que escapan de situaciones políticas adversas, arriesgan su suerte en esta parte del continente"36. Lo hemos visto, no debe sorprender esta afirmación: republicanos, liberales, fieles a sus jefes (viniendo del modelo napoleónico, no es extraña esta actitud), sus conductas afectaron sus carreras militares y provocaron, en algunos casos, sus muertes. Los conflictos internos de la independencia constituyeron el escenario perfecto para tales consecuencias: el desacuerdo entre O'Higgins y Carrera sobre cómo construir el Chile nuevo (1814-1817), la pugna entre San Martín, Alvear y Carrera en Argentina (1817-1821), la lucha por el poder entre O’Higgins y Freire en 1823-1826, la confrontación entre federalistas y unitarios en Argentina (1820-1830) y la oposición entre liberales republicanos y liberales conservadores en Chile entre 1828 y 1831. Un viajero francés, René Lesson, confirma estas situaciones diciendo "todos se quejaban de los gobiernos extremos de estas malogradas regiones desde tanto tiempo víctimas de guerras civiles" ${ }^{37}$. Cabe agregar que su actuar político generó también reacciones por parte de los que no compartían sus ideales. En 1830, el Tesorero General de la Provincia de Concepción expresaba lo siguiente: "El día es próximo en el cual echaremos estos guerreros que sirven solamente alimentar la guerra civil en vez de terminarla" 38 . Esta frase anuncia los despidos post Lircay ya mencionados. Los diplomáticos franceses del continente, como Jean Sérurier en los Estados Unidos, predice en 1818 lo que estamos describiendo y lo contextualiza: "Todo lo que queda en Europa de descontento y faccioso buscará naturalmente su punto de apoyo en América. Se establecerán relaciones en todas direcciones y un eco de rebelión repercutirá continuamente del uno al otro continente ${ }^{39}$ '. Finalmente, el historiador Luís Vitale analiza las consecuencias de la batalla de Lircay con estas palabras,

"Algunos oficiales, herederos de las ideas liberales de la ilustración francesa, con Ramón Freire, trataron de implementar entre 1823 y 1828 algunas medidas progresistas respeto de los privi-

36 Herbe Pelosi, Argentinos en Francia, franceses en Argentina, (Buenos Aires, Ciudad Argentina, 1999), 60.

37 René Lesson, Voyage autour du monde entrepris par ordre du gouvernement sur la corvette la "Coquille”, (Paris, Pourrat Éditeur, 1839), 84.

38 Lesson (1839), 98.

39 Emilio Ocampo, La última campaña de Napoleón y la independencia de América (Buenos Aires, Claridad, 2007), Carta de Sérurier a Richelieu (ministro de relaciones exteriores del rey Luís XVIII), Paris, abril de 1818, 268. 
legios de la Iglesia y de los terratenientes, aunque sin caer en el militarismo como sistema de gobierno ${ }^{40}$ ".

Estos ejemplos permiten entender la adscripción de los militares napoleónicos a bandos republicanos distintos a partir de su ideología. Se adaptan entonces a la fragmentación y restructuración del poder en las nacientes republicas y las dificultades que atraviesan relevan de su decisión, por lo tanto de su credo político.

En los países bolivarianos, el quince por ciento de los napoleónicos recibe condenas por sus involucramientos políticos. Todos los franceses presentes en la República de Cartagena (1812-1815) son profundamente republicanos, los que combaten en la "Guerra a muerte" en 1813 deben ser considerados como revolucionarios, casi jacobinos por no temer eliminar físicamente el riesgo (en este caso los españoles) tal como lo habían hecho sus antepasados con la nobleza y el clero durante la Revolución Francesa en 1793-1794. Lógicamente, una vez, terminado este período (1813-1815), tienen dificultades para reinsertarse en la vida militar de los países de la zona. Además, los partidarios de Francisco de Miranda (algunos llegaron con él en su primer intento en 1806, otros en 1811 y los últimos se juntaron con él en Cartagena) son encarcelados o alejados del ejército al momento de su arresto por Bolívar y su encarcelamiento en España en 1815. Otros deciden seguir Bolívar en los Cayos y en su campaña de reconquista a partir de 1816. Once de ellos son expulsados por el mismo Bolívar cuando es proclamado dictador jefe supremo de la República en 1819 y otros conocen el mismo destino al momento de su nombramiento como dictador del Perú en 1824. Claramente, la evolución política del libertador hacia un poder personal y absoluto contradice sus ideales. Los que le fueron fieles hasta el final pierden sus rangos a su caída y su remplazo por el general Francisco de Paula Santander. Como el en sur de América Latina, seguir un líder y su proyecto político significa asumir las consecuencias de su caída, cualquieras sean las razones. Muestran cohesión y protección mutua entre ellos aún si, por razones distintas han decidido seguir líderes

40 Luís Vitale, Intervenciones militares y poder fáctico en la política chilena, 1830-2000, Santiago, 2000, en www.mazinger.sisib.uchile (visitado en mayo de 2003). 
distintos $^{41}$. Y esto también se revela problemático. En 1816, un informe indica lo siguiente al general Antonio Nariño:

"Estos extranjeros que sin duda hablarían entre si francés, cosa que no perdonan nunca las gentes ignorantes cuando delante de ellas se habla en una lengua que no entienden, exasperan a los oficiales americanos y, con el objeto de salir de los que odiaban, tramaron una conspiración contra Serviez, Campomanes y dos o tres más para ponerlos en mal predicamento con Nariño asegurando que los extranjeros se habían confabulados para amarrarle o matarle y quitarle el mando del ejército y apoderarse de la autoridad $^{42}$ ".

Si bien, se puede leer este texto como el resultado de la xenofobia adentro de las fuerzas insurgentes, no se puede descartar el uso de este sentimiento con fines políticos con meta a reducir o eliminar representantes de bandos adversos.

Ya en 1811, su número importante en Caracas molesta los españoles: "Caracas está llena de franceses, tenemos una invasión de oficiales franceses... ${ }^{43}$ ". Entre ellos, el coronel du Cayla, los oficiales Chatillon, Colot, d'Elhuyard, Peru de Lacroix (futuro edecán de Bolívar) y Serviez (futuro general de Bolívar). Lo mismo que ocurrió a Serviez y Campomanes pasó en 1824 a los tres oficiales napoleónicos que comandan la guarnición de Santiago de Chile, Jorge Beauchef, José Rondizzoni y Benjamín Viel: Acusados falsamente de insultos hacia el parlamento y la nación por el diputado conservador Carlos Rodríguez ${ }^{44}$, son defendidos por el propio general en jefe, general Diego Benavente, aludiendo a

41 Ángel Carranza, Don Federico Brandsen, Revista de Buenos Aires, Tomo VIII, 1865, N² 29, pp. 47 52, Tomo XI, 1866 , $\mathrm{N}^{\circ} 41$, pp. $1-15$, 42, pp. 184-195, $\mathrm{N}^{\circ} 43$, pp. 322-330 y $\mathrm{N}^{\circ} 44$, pp. 464-471. Esta serie de artículos muestra las relaciones epistolares y el apoyo sistemático entre oficiales napoleónicos aunque pertenezcan a bandos distintos en Chile, Argentina y Perú.

42 Rodrigo García Estrada, La condición de extranjero en el tránsito de la colonia a la república en la Nueva Granada (1750-1830), Tesis de doctorado (Quito, Universidad Andina Simón Bolívar, 2012), 163.

43 Francisco Encina, Historia de Chile, (Santiago, Editorial Nascimento, 1913), tomo VI, 68.

44 Valentín Letelier (recopilador), Sesiones de los cuerpos legislativos de la República de Chile, 18111845, (Santiago, Imprenta Cervantes, 1889), Tomo XI, 239. 
"cuatro díscolos, vergüenzas de la patria, buscan todo medio de efectuar un trastorno. No pudiendo ganar a los jefes de los cuerpos para que los execren de honor y virtudes, se han valido de hacer correr que se van a quitar a Viel..., Beauchef... y Rondizzoni. .. A esto, Viel respondió que eran arterías movidas por los malvados que ya desesperan de sus malditas intenciones" ${ }^{\prime 4}$.

Siempre fiel a Simón Bolívar, el general Josep Sarda, catalán español al servicio de José Bonaparte hasta 1814, es uno de los últimos en visitar el libertador antes de su fallecimiento en Bucaramanga en 1830 y es expulsado del ejército en razón de su oposición a Santander en 1831. Participa en una conspiración contra este mismo en 1832. Enjuiciado, es condenado a muerte en 1832. Logra escaparse en 1833 pero es asesinado pocos días después ${ }^{46}$. Este ejemplo ilustra perfectamente los riesgos vividos por los militares (napoleónicos o no) que se involucran en política. El dieciocho por ciento de los napoleónicos fallecidos en los países bolivarianos muere ejecutado, cuando el resto fallece en combate. En los dos casos, esto demuestra su fidelidad a los líderes que escogieron y a la causa que defendieron.

En la tercera zona de estudio (México, Caribe, Centroamérica y Brasil), cuarenta y uno participan de complots, cincuenta y cinco son espías o agentes secretos, sesenta y uno son arrestados, ocho dados de baja, setenta y seis condenados, treinta y cuatro encarcelados, veintisiete expulsados, diez fusilados, cinco asesinados y dos cometen suicidio de un total de ocho cientos biografiados en esta zona. Coronel y edecán del emperador Agustín de Iturbide I, el polaco Carlos Beneski de Beaufort es un buen ejemplo de las vicisitudes de los napoleónicos en México. Integrado al ejército en 1823, teniente coronel en 1824, luego coronel, es encarcelado a la caída del Iturbide en abril acusado de haber participado en una conspiración contra el gobierno, despedido del ejército y expulsado del territorio como “aventurero, creatura del señor Iturbide". Se une a Iturbide exiliado en

45 Archivo Nacional de Chile, Santiago, Archivos varios, 1815-1833, Volumen 127, documento 33 y Correspondencia de D. Benavente, 1822-1847, Volumen 821, documento 48.

46 Patrick Puigmal. Diccionario de los militares napoleónicos durante la independencia de América, Países bolivarianos (Santiago, Biblioteca Nacional, 2015), 337-340 
Inglaterra y participa a su intento de reconquista de México como coronel y edecán. Beneski la describe de esta manera: "Napoleón corrió desde Egipto para salvar los franceses de la anarquía; Iturbide debe prontamente salir de Londres para salvar México, su patria, de la ruina y la devastación”. Pero el intento fracasa, Iturbide es fusilado y Beneski, condenado por complicidad, es encarcelado y deportado a los Estados Unidos en 1824. Como para justificar su actuar, declara entonces "detesto altamente los gobiernos monárquicos despóticos; declaro francamente ante Dios que ve los corazones que nunca hubiera acompañado al exemperador de México si lo hubiera creído un déspota enemigo de la libertad". Vuelve a pesar de la prohibición a México e integra el ejército del general Antonio López de Santa Anna con el cual combate y se distingue en Tampico en 1829. De nuevo expulsado en 1831, se une al bando conservador para ser exento de deportación y sigue su carrera militar, combatiendo en Texas con Santa Anna., hasta 1836 cuando se suicida ${ }^{47}$. Veremos luego que México verá muchos napoleónicos involucrarse en política a partir de su pertenencia a la masonería.

En la Confederación Centroamericana, Nicolás Raoul juega un papel determinante de 1824 a 1833. General en jefe, inmediatamente integrado en el bando liberal, "como casi todos los oficiales nacionales eran conservadores y que la mayoría de los francófilos pertenecían al bando liberal, Raoul de unió a estos últimos hacia los cuales sus antecedentes bonapartistas lo inclinaban desde el principio”. Entra rápidamente en conflicto con el presidente conservador Aniceto Arce, decide renunciar pero es arrestado por abandono de deber, encerrado en el castillo de Omoa (Honduras) pero vuelve poco después al puesto de comandante en jefe. Propone entonces un plan de reforma constitucional como un intento de reconciliar los bandos opuestos.

"En este proyecto de constitución liberal, Raoul muestra una evolución de las ideas de 1789 hacia las que permitieron el triunfo en

47 Puigmal (2019), pp. 256-258. Este texto incluye todas las citas de Carlos Beneski presentes en este artículo. 
Francia durante la monarquía de julio; es decir el liberalismo de la burguesía influenciado por las teorías económicas inglesas... En este sentido Raoul es también un precursor de los liberales de la reforma de 1870".

De nuevo jefe de estado mayor del general Francisco Morazán en 1829, se distingue en Guatemala y continúa el servicio a pesar de su jubilación hasta la derrota definitiva del conservador Arce en $1832^{48}$. Otro general francés lo acompaña constantemente en sus acciones, Saget, ex oficial del imperio napoleónico.

Brasil, a pesar de conocer una independencia en apariencia muy diferente -es el propio hijo del rey que dirige las tropas emancipadoras y que luego de la victoria se proclama emperador- acoge también numerosos napoleónicos quienes participan en las luchas políticas para la instauración del régimen nuevo. Militares o intelectuales (en particular artistas, libreros e impresores), conocen los mismos sobresaltos en sus vidas y carreras que el en resto de América Latina. Como en Chile y en Colombia, Hypolite Guion, teniente-coronel, es expulsado del ejército por ser extranjero en 1831. Partidario de Pedro I, es probablemente esta posición política que explica la decisión anterior. Pierre Labatut ${ }^{49}$, general y comandante en jefe del ejército independentista en 1822-1823, será también fiel a Pedro I hasta el final y será enjuiciado por tendencias liberales en 1831. De hecho, será encarcelado sin motivo claramente establecido pero probablemente por primero haber integrado esclavos a su ejército (dándoles así su libertad) y haber maltratado terratenientes durante sus campañas. No caben dudas que estos últimos, muy influyentes en Río de Janeiro aprovecharon la caída de Pedro I para obtener venganza. Guido Marliere, futuro general brasileño, es arrestado en 1811 por espionaje en beneficio del emperador $\mathrm{Na}$ poleón y denunciado como "emisario de Bonaparte y enviado por él para subvertir a estos estados". Declarado inocente y liberado, su actuar futuro

48 Patrick Puigmal. Diccionario de los militares napoleónicos durante la independencia de América, México, Centroamérica, Caribe y Brasil (Santiago, Biblioteca Nacional, 2019), 462-466

49 Patrick Puigmal, Diccionario de militares napoleónicos durante la independencia de América latina, Volumen III, México, Caribe, Centroamérica y Brasil, DIBAM, Centro Diego barros Arana, Santiago, 2019, 108-111. La biografía de Pedro Labatut incluye todas las citas presentes en este artículo. 
en pos de una sociedad nueva promoverá la integración de los indígenas y la abolición de la esclavitud lo que le valdrá la animosidad de una parte importante de la élite brasileña. Justin Crémiere y Pierre Plancher de la Noé son denunciados a su llegada en 1824 por el propio embajador monarquista francés, Jean Baptiste Maler, quien solicita "hacerlos salir del territorio por tener intenciones revolucionarias". Victor Angliviel de la Beaumelle escribe en su libro "la injusticia produce el fin de la independencia" en el epígrafe del texto lo que no se puede leer de otra manera que como una advertencia al régimen imperial. Finalmente, Eugene Garay de Monglave es inmediatamente denunciado a su llegada a Brasil por el mismo personaje por "manifestar opiniones poco favorables a la monarquía ${ }^{51 "}$ ". Maler agrega "uno puede temer y encontrar líderes en un pequeño grupo de ellos: aquellos como Garay deben ser puestos bajo vigilancia ${ }^{52 " . ~ S i ~ b i e n ~ B r a s i l ~}$ no conoce las luchas internas y fratricidas de los otros países de América Latina, es la evolución política del propio líder de la independencia, Pedro I, que provocará consecuencias sobre las vidas de los napoleónicos. Lo hemos visto, sus partidarios sufrieron rupturas brutales de carrera a su caída; muchos, que lo apoyaron al inicio de su poder, se alejaron de él cuando se dieron cuenta de su evolución hacia un actuar cada vez más unipersonal y conservador; otros, siempre opuestos al establecimiento de un imperio como resultado de la independencia, fueron constantemente perseguidos provocando en general su exilio definitivo.

La influencia política se revela siempre limitada si no se acompaña de acciones para obtener más partidarios. En este sentido, la educación constituye, indudablemente, una herramienta muy eficaz. Pero cuando evocamos la educación, no pensamos solamente en la educación formal a través de establecimientos, colegios, liceos o universidades. Pensamos en la prensa como vector de ideas y en la pertenencia en movimientos como la masonería o el carbonarismo que tienen esta misma educación como un

50 Victor Angliviel de la Beaunulle, "De l'empire du Brésil sous les rapports politiques et commerciaux" (Paris: Imprimerie du Fain, 1823), 124.

51 Patrick Puigmal, Diccionario, Volumen III, 177-179.

52 Todos los elementos citados para estos napoleónicos en Brasil vienen de Puigmal (2019), pp. 86-88 para Angliviel de la Beaumelle, p. 112 por Cremiere y Plancher, pp. 135-136 para Guion, pp. 145-149 para Labatut, pp. 174-175 para Marliere y pp. 177-179 para Garay de Monglave. 
factor de cambio societal. El momento de la independencia en América latina corresponde a un importante desarrollo de estos tres elementos y, sistemáticamente, constatamos la presencia napoleónica como impulsadora, creadora o colaboradora.

La prensa, casi ausente en América latina antes de la independencia, nace al alero de los primeros líderes y, a menudo, revela el inicio del movimiento como es el caso de la "Aurora de Chile" de Camilo Henríquez en Chile desde 1810. Pero entre 1820 y 1830, son más de cien periódicos que van a aparecer en Chile, de duración desigual y de muy diversas opiniones políticas. Estos periódicos reflejan el debate político, lo alimentan y permiten también la aparición y/o confirmación de algunos líderes. Son, antes que todo, la manera de presentar ideas y de provocar el debate. Pedro Chapuis, capitán de caballería de la Guardia Imperial y masón, es un profesional del asunto: ha creado órganos de prensa durante la rebelión liberal de España en 1823, el gobierno de Pedro I en Brasil (1824), las luchas internas de Chile (1825-1827) y lo hará en el Perú (1828-1832). En Brasil y Chile, su "Verdadero Liberal" es el portavoz del liberalismo republicano, del desarrollo de la educación para todos y de un sistema judicial igualitario. Visto como un "peligroso exaltado", Chapuis paga sus tomas de posición con exilios sucesivos ${ }^{53}$. Lo interesante es que su trayectoria se corresponde con la de otros napoleónicos en el continente, en particular con un grupo de italianos, masones y carbonarios, que actúan de la misma manera en México. Linati, Galli, Ceruti y Santangelo, a través del "Iris Republicano" en 1826 reproducen las mismas ideas, a veces los mismos artículos. En México, como en Chile, estos diarios plasman la oposición total entre ideologías y la brutalidad del debate, el cual siempre termina con el exilio de los más republicanos ${ }^{54}$. En Brasil, los napoleónicos son omnipresentes en los sectores de la edición, de la imprenta y de la prensa. Algunos son señalados

53 Patrick Puigmal, Diccionario, Volumen I, 129-131.

54 Para más información sobre la prensa durante la independencia de Chile y México, ver Patrick Puigmal, Napoleónicos, europeos y liberales, en la independencia americana: dos casos de estudio, Chile y México, Revista Tiempo Histórico, Universidad Academia Humanismo Cristiano, Santiago, (2012): $15-35$ 
por tener "un espíritu demasiado francés y pro napoleónico 55 ", otros son por lo mismo objetos de denuncias por parte del embajador francés en Río, pero todos participan a través de la impresión de libros y diarios del debate político. Plancher de la Noé, bonapartista convencido apoya a Pedro I porque según él el modelo imperial se adapta muy bien a la evolución de la sociedad. Esto en oposición total con lo que plantea Chapuis. Pero los dos decidieron "buscar asilo en un país de sus simpatías a causa de las numerosas condenaciones políticas que tuvieron que enfrentar”. Plancher escribe sobre
"Napoleón como el mayor hombre de nuestro siglo... la necesi- dad de instruir y preparar los bravos brasileños para que puedan apreciar las ventajas de su regeneración política... Pagaré con mi persona y con todo lo que poseo mi adhesión a la causa de Brasil, mi patria adoptiva" 56 .

Mientras Chapuis critica Pedro I apuntando a "sus errores desde su llegada al poder y que su poder no viene del pueblo pero de una gracia otorgada por Joao VI". Sufre entonces su expulsión, apoyada por Plancher por ser "un anarquista expulsado de todos los países de Europa a causa de sus principios republicanos y llegado a Brasil solamente para fomentar la revolución ${ }^{57}$. Vemos en este caso napoleónicos de opinión política distinta, aunque ambos partidarios de la independencia, oponiéndose a través de sus órganos de comunicación. Aun cuando no crean o poseen periódicos, los napoleónicos publican opiniones en periódicos como es el caso de Benjamín Viel en el "Diarios de los militares constitucionalistas" en Chile en 1831 para denunciar los abusos ocurridos luego de la derrota de Lircay o como Nicolás Raoul al momento de presentar su plan de reforma constitucional en la Confederación Centroamericana y Josep Sarda para defender el concepto centralista propuesto por Simón Bolívar para la Gran Colombia en 1828. Claramente, son militares pero tienen ideologías

55 Patrick Puigmal, Diccionario, Volumen I, 129-131.

56 Patrick Puigmal, Diccionario, Volumen III, 142-144.

57 Para más información sobre la prensa napoleónica en Brasil ver Patrick Puigmal, Brasil bajo influencia napoleónica y francesa. Los mensajeros de la independencia : militares, libreros y periodistas, Revista Historia, Pontificia Universidad Católica de Chile, Santiago, Vol. 1 No. 46 (2013): 113-151 
definidas y no temen en expresarlas aunque tengan luego que pagar el precio de su libertad de expresión.

Casi todos los países nuevos carecen de un sistema educativo nacional. La educación al momento de la independencia está en manos de la Iglesia. Los Estados nuevos no están en capacidad de generar rápidamente las condiciones para el establecimiento de un sistema educativo nacional y van a apoyar las iniciativas de numerosos napoleónicos, quienes gracias su experiencia en el liceo imperial van a desarrollar un modelo similar aunque de origen británico, el sistema Lancaster ${ }^{58}$. Tanto Bolívar como Freire, Pedro I y Santa Anna van a acoger estos establecimientos: más de sesenta se crean en América Latina, casi todos creados por militares napoleónicos. Es el caso del Colegio de Santiago creado por Pedro Chapuis en 1827. Entre México y Brasil, son doscientos cincuenta los que se involucran en la educación, la prensa y la edición. Plasman sus idearios en el contenido de la enseñanza. En Colombia y Venezuela, más de treinta establecimientos son creados bajo el alero de napoleónicos ${ }^{59}$.

Lo hemos evocado en varias oportunidades en este texto: muchos napoleónicos pertenecen desde Europa a la masonería o al carbonarismo (los italianos). Lejos de abandonar estos movimientos a su llegada al continente, van a aplicar sus conceptos y participar en la creación de múltiples logias. Carlos Renard y Juan Zeghers participan de la primera logia creada en Chile "Filantropía chilena" en 1827. Los italianos en México son todos masones y es desde este movimiento que presentan públicamente sus ideas en los periódicos que administran. En Brasil, Pedro Chapuis, Pierre Plancher, Pierre Dalbin, Justin Cremiere y la casi totalidad de los involucrados en las actividades de edición pertenecen también a este movimiento ${ }^{60}$. Pero, indudablemente, es en los países bolivarianos (principalmente en Colombia y Venezuela) que la masonería va a conocer su más importante desarrollo. Miguel Cerneau crea en 1824 la Gran Logia Masónica de

58 Los dos sistemas se caracterizan en particular por un respeto estricto al orden y una clara rigidez militar.

59 Patrick Puigmal, Diccionario, Volumen II, 50-53.

60 Patrick Puigmal, Diccionario, Volumen III, 82-83, 135-136 y 142-144. 
Colombia que reagrupa más de treinta logias repartidas en todo el país y en las cuales se encuentran muchos napoleónicos tales como Luís Rieux o Antoine Leleux. Muchos de ellos eran ya masones antes de llegar como el general Michel Brayer, maestro de la logia "Les amis incorruptibles" en Francia ${ }^{61}$. Son más de treinta, solamente en Chile, los masones incorporados al movimiento en Europa. Walter Bruyere Ostells escribe a este propósito: "los oficiales napoleónicos tienen la impresión y la voluntad de pertenecer a un mismo movimiento que prendería fuego a Europa y América en contra de las monarquías despóticas" ${ }^{\circ 2}$.

Es evidente que cada uno de los temas abordados en este texto podría ser el objeto de un artículo particular pero como lo planteamos al inicio, se trataba en esta ocasión de demostrar un fenómeno histórico, la influencia política de los militares napoleónicos en el proceso de emancipación de América Latina, fenómeno no estudiado y por lo tanto no dimensionado hasta ahora. Pensamos haber cumplido con nuestra meta a través de la descripción de los roles militares de primer nivel que permitieron a los dos mil personajes que hemos podido identificar en este espacio entre 1810 y 1835 ser también actores de la formación de los nuevos Estados. Sus involucramientos políticos, sus inmersiones en los mundos de la prensa, de la educación y su pertenencia a la masonería fueron, de hecho, maneras distintas para obtener el mismo fin: obtener lo que no habían podido obtener en Europa, la creación de repúblicas liberales. Aquí también se puede abrir un nuevo debate como para prologar este estudio: ¿El modelo político que se impone en América latina al inicio de los años 1830 corresponde plenamente a lo planteado por los napoleónicos? Cualquiera sea la respuesta, estamos en presencia de un movimiento que se puede resumir en una expresión: de civiles militarizados para obtener la independencia, se transformaron en militares civilizados ${ }^{63}$ para construir un modelo societal nuevo.

61 Patrick Puigmal, Diccionario, Volumen I, 115-117.

62 Walter Bruyere Ostells, (2009), 19.

63 La expresión "militares civilizados" significa militares que dejaron su estado militar para volver a la vida civil. 


\section{Bibliografía}

\section{Libros:}

Alamán, Lucas. Historia de México (Ciudad de México, Editorial Jus, 5 volúmenes, 1849-1852)

Angliviel de la Beaumelle, Victor. De l'Empire du Brésil sous les rapports politiques et commerciaux (Paris, Imprimeris du Fain, 1823).

Armitage, John. Historia do Brasil desde a chegada da familia de Braganza em 1808 até a abdicacao do emperador D. Pedro I em 1831 (Río de Janeiro, Typ. Imp. E. Const. De Villeneuve e comp., 1837)

Barros Arana, Diego. Historia general de Chile (Santiago, Rafael Jover editor, 16 volúmenes, 1884-1902)

Brandsen, Federico. Diario de la campaña del sur de Chile hasta el Bio Bio desde el 5 de noviembre de 1818 hasta el 1 de marzo de 1819 (Buenos Aires, Federico Santa Colonia Brandsen, 1910)

Bruyere Ostells, Walter. La Grande Armée de la libertad (Paris, Taillandier, 2009)

Cartes Montory, Armando y Puigmal, Patrick. De la Alsacia al Bio Bio, el oficial napoleónico Frédéric de Brandsen en las campañas de la independencia de Chile (Concepción, Editorial Pencopolitana, 2008) Carranza Ángel, Don Federico. Brandsen, revista de Buenos Aires, Historia americana, literatura y derecho, Imprenta de mayo, Buenos Aires, Tomo VIII, año 3, 1865, N²9, pp. 47-52, Tomo XI, año IV, 1866, $\mathrm{n}^{\circ} 41$, pp. $1-16, \mathrm{~N}^{\circ} 42$, pp. $184-195, \mathrm{~N}^{\circ} 43$, pp. $322-330, \mathrm{~N}^{\circ} 44$, pp. 464-471.

Encina, Francisco. Historia de Chile (Santiago, Editorial Nascimento, Tomo VI, 1913)

Guizot, Francois. Histoire de la civilisation en France (Paris, Didier Libraire-Éditeur, 4 volúmenes, 1830)

Ibañez, A. y Medina José Toribio. Hoja de servicios de Don José Rondizzoni (Santiago, Imprenta del Ferrocarril, 1865)

Lesson, René. Voyage autour du monde entrepris par ordre du gouvernement sur la corvette la "Coquille” (Paris, Pourrat Éditeur, 1939)

Letelier, Valentín. Sesiones de los cuerpos legislativos de la república de Chile, 1811-1845 (Santiago, Cervantes, 1889) 
Mitre, Bartolomé. Historia de Belgrano y la independencia de Argentina

(Buenos Aires, Editorial Juventud argentina S. A., 1859)

Mitre, Bartolomé. Historia de San Martín y la emancipación sudamericana

(Buenos Aires, Imprenta de la nación, 3 volúmenes, 1887-1890)

Moradiellos, Enrique. El oficio del historiador (Madrid, Siglo XXI, 2010)

Ocampo, Emilio. La última campaña de Napoleón y la independencia de América (Buenos Aires, Claridad, 2005)

Pelosi, Herbe. Argentinos en Francia, franceses en Argentina (Buenos Aires, Ciudad argentina, 1999)

Persat, Maurice. Mémoires de Persat, 1806-1844 (Paris, Pon-Nourrit, 1910) Puigmal, Patrick. Diccionario de los militares napoleónicos durante la independencia de América, Argentina, Chile y Perú ( Santiago, Biblioteca Nacional, 2013)

Puigmal, Patrick. Diccionario de los militares napoleónicos durante la independencia de América, Países bolivarianos (Santiago, Biblioteca Nacional, 2015)

Puigmal, Patrick. Diccionario de los militares napoleónicos durante la independencia de América, México, Centroamérica, Caribe y Brasil (Santiago, Biblioteca Nacional, 2019)

Diálogo de sordos entre José de San Martín y Michel Brayer (Osorno, Universidad deLos Lagos, 2003)

Puigmal, Patrick. ¡Diablos, no pensaba en Chile hace tres años (Osorno, Universidad de Los Lagos, 2006)

Restrepo, Juan Manuel. Historia de la revolución de Colombia en América meridional (Besancon, Imprenta de M. Jacquin, 4 volúmenes, 1858) Rodríguez Ballesteros, José. Historia de la revolución y guerra de la independencia del Perú desde 1818 hasta 1866 (Santiago, Biblioteca Nacional, Tomo XXXIV, 1949)

Rondeau, José. Resumen documentado de la causa seguida y sentencia en el tribunal de la comisión militar de esta capital contra los reos Carlos Robert, Juan Lagresse, Agustín Dragumette, Narciso Parchappe y Marcos Mercher (Buenos Aires, Imprenta independencia, 1819)

Sábato, Ernesto. Sobre héroes y tumbas (Buenos Aires, Sudamericana, 1961) 
Thiers, Adolphe. Histoire du Consulat et de l'Empire (Paris, Paulin Libraire-Éditeur, 20 volúmenes, 1846-862)

Thiers, Adolphe. Histoire de la révolution (Paris, Furne et compagnie Libraires-Éditeurs, 10 volúmenes, 1851-1853)

Vicuña Mackenna, Benjamín. La guerra a muerte: memoria sobre las últimas campañas de la independencia de Chile (Santiago, Imprenta Nacional, 1868)

\section{Artículos:}

Campos Harriet, Fernando. "Soldados de Napoleón en la independencia de Chile" Memorial del ejército de Chile, (Santiago, N 350, Julio-Agosto de 1969, pp. 45-78).

Puigmal, Patrick. "Napoleónicos, europeos y liberales en la independencia americana: dos casos de estudio, Chile y México" Revista Tiempo Histórico (Santiago, Universidad Academía Humanismo Cristiano, $2^{\circ}$ semestre 2012, pp. 15-35).

Puigmal, Patrick. "Brasil bajo influencia napoleónica y francesa. Los mensajeros de la independencia: militares, libreros y periodistas" Revista Historia (Santiago, Pontificia Universidad católica de Chile, $\mathrm{N}^{\circ} 46$, Vol. 1, enero-julio de 2013, pp. 113-151).

Andrés, Rodríguez. "Ambrosio Cramer, un soldado de la libertad” Boletín de la Academia nacional de Historia (Buenos Aires, Tomo XXVII, 1956)

\section{Tesis:}

García Estrada Rodrigo, La condición de extranjero en el tránsito de la colonia a la república en la Nueva Granada, 1750-1830 (Tesis de doctorado, Quito, Universidad Andina Simón Bolívar, 2012)

Fuentes de archivo:

Texto anónimo y manuscrito atribuido a Santiago Roul, Santiago, Biblioteca Nacional, Sala Medina, AAG 2359.

82 Carta de renuncia de Deslandes, Archivo Nacional de Chile, Santiago, Ministerio de la Guerra de Chile, Volumen 19, Documento 27 y volumen 59. 
Correspondencia del coronel Benavente, Archivo Nacional de Chile, Santiago, Archivos varios 1815-1833, Volumen 127, Documento 33 y 1822-1847, Volumen 821, Documento 18.

Nicolás, Joly. Archivo General de la Nación, Colombia, Sección venezolana, 13, archivo de la Gran Colombia, Guerra y Marina, 448.

Cartas de Benoit Chasseriau, Archive Nouvion/Chasseriau, Fondo de dos mil documentos manuscritos de Benoit Chasseriau hospiciado al autor por su descendiente Jean Baptiste Nouvion.

\section{Publicaciones en internet:}

Maldonado, Claudio. El ejército chileno en el siglo XIX: génesis histórico del ideario heroico, 1810-1885, www.geocities.com/capitolhi1l/7109/eje1.html (visitado en abril de 2003.

Vitale, Luis. Intervenciones militares y poder fáctico en la política chilena, 1830-2000, Santiago, 2000, www.mazinger.sisib.uchile (visitado en mayo de 2003).

Para citar este artículo: Puigmal, Patrick Jacques. "Militares y militantes políticos: el actuar de los napoleónicos en la construcción republicana en América latina durante la independencia (1810-1835)", Historia Caribe, Vol. XIV No. 35 (Julio-Diciembre 2019): 55-83. DOI: http://dx.doi. org/10.15648/hc.35.2019.3 